\title{
LA ORIGINALIDAD EN LA MÚSICA Y LA IMAGEN: UNA APROXIMACIÓN Y ESTUDIO DE DIVERSOS SUPUESTOS EN EL DERECHO ESPAÑOL
}

FRANCISCA RAMÓN FERNÁNDEZ ${ }^{* *}$

\section{INTRODUCCIÓN}

En el ámbito de la propiedad intelectual, la protección siempre se concede a lo que se considera como obra original, si bien en diversos supuestos se pone en duda la originalidad de la misma para ser protegida. Nos referimos a los supuestos de plagio y fraude. En el presente trabajo se reflexiona acerca de la originalidad en la música y la imagen y su sincronización en la obra audiovisual, y se analizan, desde el punto de vista legislativo y jurisprudencial (en especial, del Tribunal Supremo español), los distintos supuestos en los que falta dicha originalidad, bien porque se ha plagiado una obra, bien porque se ha producido una suplantación o fraude en la identidad del autor, con la finalidad de aportar una perspectiva complementaria a dicho concepto.

Recuérdese cuanto decía Brian de Palma en El fantasma del paraiso, de 1976: “Tu voz! ¡Me prometiste tu voz! ¿No recuerdas nuestro contrato?”. Esta película trata de la historia de Winslow Leach, un compositor cuya obra es robada por Swan, magnate de la música ${ }^{1}$. Y cabe mencionar asimismo el caso del plagio cinematográfico de la película Letty Lynton, de $1932^{[2]}$.

\footnotetext{
* Trabajo realizado en el marco del Proyecto I+D Excelencia MIneco der2015-65810-P (2016-2018), y Proyecto Programa Prometeo para Grupos de Investigación de Excelencia de la Conselleria de Educación, Cultura y Deporte, gvprometeori2015-014.

** Profesora titular de Derecho Civil, Universitat Politècnica de València (España). Contacto: frarafer@urb.upv.es Fecha de recepción: 9 de enero de 2018. Fecha de aceptación: 15 de mayo de 2018. Para citar el artículo: Ramón Fernández, F. "La originalidad en la música y la imagen: una aproximación y estudio de diversos supuestos en el derecho español", Revista La Propiedad Inmaterial n. ${ }^{\circ}$ 25, Universidad Externado de Colombia, enero-junio 2018, pp. 5-25. DoI: https://doi.org/10.18601/16571959.n25.01

1 Disponible en: http://elpais.com/elpais/2016/03/10/icon/1457610637_611325.html [consultada el 10 de septiembre de 2017].

2 Guiralt Gomar, Carmen y Carratalá, Adolfo. "El plagio cinematográfico de Letty Lynton (1932) y su impacto en la industria fílmica estadounidense: análisis del proceso judicial y de su cobertura mediática”, Observatorio (OBS), vol. 10, n. ${ }^{3}$ 3, 2016 , pp. 1-19, disponible en: http://obs.obercom.pt/index.php/obs/article/view/991 [consultado el 9 de septiembre de 2017].
} 
Se tratará también de los casos de la obra derivada y la obra transformada, así como de los denominados "arreglos musicales" y de su diferenciación del plagio ${ }^{3}$.

Los principales objetivos planteados en el trabajo son los siguientes:

- Reflexionar sobre la originalidad en el concepto de obra, tal y como se contempla en la legislación de propiedad intelectual española. Junto a ello, se atenderá a la obra artística, que se integra dentro del concepto de creación protegida por la ley, extendiéndonos a la obra audiovisual, comprensiva de la música y la imagen.

- Adelantar un análisis legislativo y jurisprudencial de los supuestos en los que falta la originalidad por plagio.

- Identificar los casos en los que se ha suplantado o se ha realizado un fraude en la identidad del autor.

La metodología empleada en el presente trabajo es la habitual en los estudios de naturaleza jurídica, a partir del análisis del marco normativo aplicable, para deslindar los conceptos fundamentales, en este caso la imagen, el sonido y la obra audiovisual, así como la distinción entre originalidad y plagio. Para una mejor comprensión se completa el estudio con diversos casos prácticos reales resueltos por la jurisprudencia respecto de si existe o no originalidad para la protección de la obra en la que la imagen y la música son parte de ella.

\section{MARCO LEGISLATIVO APLICABLE}

A continuación se presenta la normativa específica que regula la propiedad intelectual en España:

1. Real Decreto Legislativo 1/1996, de 12 de abril, por el que se aprueba el texto refundido de la Ley de Propiedad Intelectual, regularizando, aclarando y armonizando las disposiciones legales vigentes sobre la materia (en adelante, TRLPI $)^{4}$.

2. Ley $23 / 2006$, de 7 de julio, por la que se modifica el texto refundido de la Ley de Propiedad Intelectual, aprobado por el Real Decreto Legislativo 1/1996, de 12 de abril. ${ }^{5}$

3. Ley 19/2006, de 5 de junio, por la que se amplían los medios de tutela de los derechos de propiedad intelectual e industrial y se establecen normas procesales para facilitar la aplicación de diversos reglamentos comunitarios (BOE n. ${ }^{\circ} 134$, de 6 de junio de 2006).

4. Ley $21 / 2014$, de 4 de noviembre, por la que se modifica el texto refundido de la Ley de Propiedad Intelectual, aprobado por Real Decreto Legislativo 1/1996, de 12 de abril, y la Ley 1/2000, de 7 de enero, de Enjuiciamiento Civil (BOE n. ${ }^{\circ}$ 268 , de 5 de noviembre de 2014), que protege al autor de una obra artística por el

3 Galacho Abolafio, Antonio Francisco. La obra derivada musical. Entre el plagio y los derechos de autor, Pamplona, Aranzadi, 2014.

4 BOE n. ${ }^{\circ}$ 97, de 22 de abril de 1996.

5 BOE n. ${ }^{\circ} 162$, de 8 de julio de 2006. 
solo hecho de crearla (comprendiéndose las composiciones musicales, coreografías y audiovisuales).

5. Real Decreto-Ley 12/2017, de 3 de julio, por el que se modifica el texto refundido de la Ley de Propiedad Intelectual, aprobado por el Real Decreto Legislativo 1/1996, de 12 de abril, en cuanto al sistema de compensación equitativa por copia privada (BOE n. ${ }^{\circ} 158$, de 4 de julio de 2017).

6. Real Decreto-Ley $2 / 2018$, de 13 de abril, por el que se modifica el texto refundido de la Ley de Propiedad Intelectual, aprobado por el Real Decreto Legislativo 1/1996, de 12 de abril, y por el que se incorporan al ordenamiento jurídico español la Directiva 2014/26/UE del Parlamento Europeo y del Consejo, de 26 de febrero de 2014, y la Directiva (UE) 2017/1564 del Parlamento Europeo y del Consejo, de 13 de septiembre de 2017 (BOE n. ${ }^{\circ}$ 91, de 14 de abril de 2018).

\section{IMAGEN, SONIDO Y OBRA AUDIOVISUAL: SU DISTINCIÓN}

El TRLPI considera hecho generador de la propiedad intelectual la creación de una obra original por parte del autor. Dentro del concepto de creación están incluidos distintos tipos de obra, incluyéndose las composiciones musicales, con o sin letra, las obras dramáticas y dramático-musicales, las coreografías, las pantomimas y las obras teatrales, las obras cinematográficas y cualesquiera otras obras audiovisuales.

El artículo 86 TRLPI contiene, en el título referente a obras cinematográficas y demás obras audiovisuales, una definición de obra audiovisual:

... creación expresada mediante una serie de imágenes asociadas, con o sin sonorización incorporada, que estén destinadas esencialmente a ser mostradas a través de aparatos de proyección o por cualquier otro medio de comunicación pública de la imagen y del sonido, con independencia de la naturaleza de los soportes materiales de dichas obras.

Por tanto, cuando se habla de obra artística no se circunscribe a la obra pictórica o escultórica, por ejemplo, sino que se extiende a la cinematográfica como una clase dentro de la denominada obra audiovisual. También es necesario distinguir entre la obra que incorpora solo imagen, o solo música o sonido, y lo que se conoce como obra audiovisual, que sería el género que incluiría a las anteriores, y que a su vez formaría parte de lo que se denomina creación artística.

Cuestión distinta es la diferenciación entre grabación y obra audiovisual, ya que, como se verá en el siguiente apartado, la impronta del autor determina que la obra sea original para su protección, evitando que se pueda confundir una actividad mecánica con la creación de un sujeto. Así, es el artículo 120 TRLPI el que establece precisamente que la diferenciación se encuentra en el concepto de originalidad: "1. Se entiende por grabaciones audiovisuales las fijaciones de un plano o secuencia de imágenes, con o sin sonido, sean o no creaciones susceptibles de ser calificadas como obras audiovisuales en el sentido del artículo 86 de esta Ley". 


\section{CONCEPTO DE ORIGINALIDAD Y DIFERENCIACIÓN CON EL PLAGIO.}

\section{EL DERECHO DE CITA EN LA LEGISLACIÓN ESPAÑOLA}

Se protege al autor de una obra artística por el solo hecho de su creación, de la impronta que deja el sujeto sobre la obra. Dentro de la categoría de obra artística se incluyen las composiciones musicales, las coreografías y las obras audiovisuales ${ }^{6}$ No hay que olvidar que la protección siempre se concede a lo que se considera como original ${ }^{7}$. Sin embargo, hay supuestos, como son los casos de presunto plagio $y$ fraude ${ }^{8}$, en los que se pone en duda que la obra sea original $y$, por tanto, que se pueda proteger'.

De otra parte, la doctrina indica que para la protección debe existir "creatividad humana", lo que inmediatamente excluiría las obras fruto de actividad realizada íntegramente por un dispositivo informático, una máquina, un animal o por la naturaleza ${ }^{10}$. La norma no define qué se entiende por originalidad, ni tampoco define el plagio como tal; sin embargo, la doctrina se ha ocupado de aportar alguna definición de lo que se ha de entender por "original", que se debe distinguir de lo que se considera como creación re-contextualizada. Así, López ${ }^{11}$ afirma:

6 Ramón Fernández, Francisca. "La protección de los derechos de autor de las fotografías y la prestación del consentimiento", Revista Aranzadi de Derecho y Nuevas Tecnologías, n.o 31, 2013, pp. 47-74.

7 Como indica Fernández Sarasola, Ignacio. "Plagio científico y vulneración de derechos fundamentales", en Teoría y Realidad Constitucional, n. ${ }^{\circ}$ 20, 2017, p. 387, disponible en: http://revistas.uned.es/index.php/Trc/article/view/20923/17397 [consultado el 19 de abril de 2018]: "La conciencia de los plagios y la consolidación del término con el que designarlos se remonta en España al siglo xviı. En 1788, Esteban Terreros recogía la voz en su Diccionario Castellano con las voces de Ciencias y Artes, con una definición que todavía hoy reputamos válida: 'Plagiar: hurtar los pensamientos ajenos para publicaros por propios'. Y añadía que 'el plagiar es muy villano””.

8 Supuestos que hay que diferenciar de otros como el collage, la parodia o la alusión. Cfr. Valicenti, Ezequiel Andrés. "Los usos creativos de obra protegida por el derecho de autor frente al derecho al acceso al arte y a la cultura. Razones para pensar una nueva excepción”, Cartapacio de Derecho: Revista Virtual de la Facultad de Derecho, n. ${ }^{\circ}$ 0, 2017, p. 9, disponible en: http://www.cartapacio.edu.ar/ojs/index.php/ctp/article/view/1522/2031 [consultado el 19 de abril de 2018]. Se refiere al plagio creativo Soler Benito, Cristina. Propiedad intelectual en las artes escénicas, tesis doctoral dirigida por Pau Monterde, Francesc Foguet i Boreu, Universitat Autònoma de Barcelona, Barcelona, 2016, p. 266, disponible en: https:// ddd.uab.cat/pub/tesis/2016/hdl_10803_381261/csb1de1.pdf [consultado el 19 de abril de 2018].

9 Cfr. distintos supuestos en Ramón Fernández, Francisca. "La obra cinematográfica y audiovisual: fronteras reales e imaginarias en el ámbito jurídico”, en Fronteras reales, fronteras imaginadas, Alicante, Letra de palo, 2015, pp. 363-377; Íd., "El concepto de la originalidad en la videodanza: una cuestión de pasos e imagen", en Proceedings of the International Screendance Meeting, Valencia, Universitat Politècnica de València, 2016, pp. 131-140, disponible en: http://www.lalibreria.upv.es/portalEd/UpvGEStore/products/p_6352-1-1 [consultado el 8 septiembre de 2017].

10 García Sedano, Tania. "Análisis del criterio de originalidad para la tutela de la obra en el contexto de la Ley de Propiedad Intelectual", Anuario Jurídico y Económico Escurialense, n. ${ }^{\circ}$ 49, 2016, p. 258, disponible en: http://www.rcumariacristina.net:8080/ojs/ index.php/AJEE/article/view/269/pdf [consultado el 19 de abril de 2018].

11 López Farjeat, Luis Xavier. "Falsificación, apropiación y plagio. Reflexiones a partir de La transfiguración del lugar común”, Páginas de Filosofía, vol. 16, n. ${ }^{\circ} 19,2015$, pp. 58-79, disponible en: http://revele.uncoma.edu.ar/htdoc/revele/index.php/filosofia/article/view/979 [consultado el 10 de septiembre de 2017]. 
En el mundo del arte podemos encontrar cantidad de ejemplos en los que, efectivamente, un artista se apropia de la creación de otro y la re-contextualiza. Muchas obras contemporáneas nos han habituado a este tipo de prácticas. Sin embargo, también hay varios casos en los que el problema no se resuelve de una manera tan sencilla. En su película, Copia fiel (2012), el cineasta iraní Abbas Kiarostami se vale de una discusión que pertenece al terreno de la filosofía del arte para exhibir el modo en que nos apropiamos de distintas formas de interpretar la vida y las re-contextualizamos constantemente. Los protagonistas son una galerista francesa y un escritor inglés. Éste ha escrito un libro titulado Olvida el original y obtén sólo una buena copia, cuya tesis es que la copia tiene un valor por sí misma porque nos lleva al original y, de esta forma, certifica el valor de éste. El autor discute el significado del término "originalidad". Si en algo acierta es en que la palabra "original" suele tener entre nosotros connotaciones positivas ya que alude a "lo auténtico", "lo genuino", "lo confiable" y, por lo tanto, se contrapone a "lo falso", a "lo imitado".

Cabe preguntarse: ¿qué es el plagio? La jurisprudencia se ha pronunciado sobre ello en distintas sentencias, entre las que podemos destacar la STs 1716/2008, de 18 de diciembre de $2008^{[12]}$, ponente: D. Xavier O’Callaghan Muñoz, en la que se indica que es un concepto de carácter jurídico y que la jurisprudencia ha mantenido su concepto, evitando ampliaciones que podrían ser inaceptables.

Se refiere al plagio, en la citada sentencia, como "copia sustancial", entrañando una "actividad material mecanizada y poco intelectual y menos creativa, carente de toda originalidad". Por ello, no hay plagio cuando puede apreciarse que se trata de "dos obras distintas y diferenciables, aunque tengan puntos comunes de exposición" o tengan "múltiples e innegables coincidencias" que se refieran, no a coincidencias estructurales básicas y fundamentales, sino "accesorias, añadidas, superpuestas o modificaciones no trascendentales"13.

La doctrina se ha ocupado en numerosas ocasiones de tratar el plagio y ahondar en los motivos por los que se produce, y en la necesaria cita de las fuentes ${ }^{14}$. Como indica aquella ${ }^{15}$, el origen de la terminología se encuentra en el término

12 Disponible en: http://www.poderjudicial.es/search/contenidos.action?action=contentpdf\&data basematch $=$ TS\&reference $=4273061 \&$ links $=\% 22$ plagio $\% 22 \&$ optimize $=20090205 \&$ publicinterface $=$ true [consultado el 10 de septiembre de 2017].

13 Más ampliamente, Ramón Fernández, Francisca. "La redefinición de las excepciones en materia de propiedad intelectual. Derecho de cita, plagio e internet”, en Libertad de expresión e información en internet. Amenazas y protección de los derechos personales, Lorenzo Cotino Hueso y Loreto Corredoira Alfonso (coords.), Madrid, Centro de Estudios Políticos y Constitucionales, 2013, pp. 233-258; Íd. "Propiedad intelectual, obra coreográfica y video-danza", en Ponencias II Encuentro Internacional de Film de Danza 2015, 25 de septiembre de 2015, Alicante, L'Eixam, 2015, pp. 29-43.

14 Arévalo Molina, Julio. "Qué es el plagio y cómo detectarlo", en Desiderata, n. ${ }^{\circ}$ 6, 2017, pp. 24-26., disponible en: http://desiderataonline.com/ [consultado el 6 de septiembre de 2017].

15 Ruipérez García, Germán y García Cabrero, José Carlos. "Plagio e integridad académica en Alemania", Comunicar: Revista Cientifica Iberoamericana de Comunicación y Educación, n.o 48, 2016, pp. 9-17, disponible en: https:/www.revistacomunicar.com/index.php ?contenido $=$ detalles $\&$ numero $=48 \&$ articulo $=48-2016-01$ [consultado el 5 de septiembre de 2017]. 
latino "plagium", relacionado con el griego " $\pi \lambda \alpha \gamma \operatorname{los",~entendido~como~engaño-~}$ so, también en la aceptación de robo o apropiación indebida o falsificación. Los elementos que intervienen son la utilización no autorizada de la obra ajena y la falsa atribución de la autoría ${ }^{16}$.

Dicha conducta no puede ser solo por parte de terceros, sino, incluso, del propio autor, que se copia a sí mismo, en el denominado auto-plagio ${ }^{17}$ : se considera como tal la conducta en la que un autor vuelve a utilizar sus escritos y los presenta como obra inédita u original, sin citar ni referenciar sus propias publicaciones. Sin embargo, esta opinión no es unánime, ya que, como indica Spinak ${ }^{18}$, incluso insertando la referencia no se alcanza a conocer cuál es la dimensión de lo que se autocopia.

El plagio no tiene por qué ser total, también puede realizarse de forma parcial, y hay que atender a lo indicado en el artículo 18 TRLPI, respecto a la reproducción, que se considera como la fijación directa o indirecta, provisional o permanente, por cualquier medio y en cualquier forma, de toda la obra o de parte de ella, que permita su comunicación o la obtención de copias. Como ha señalado la SAP Barcelona de 29 de noviembre de $2011^{[19]}$, ponente: D. Ignacio Sancho Gargallo, respecto al plagio, este da lugar a:

... "un estado de apropiación y aprovechamiento de la labor creativa y esfuerzo ideario ó intelectivo ajeno" (sTs 28 de enero de 1995, EDJ 1995/361; reiterado más tarde por ssTs 17 de octubre de 1997, EDJ 1997/7670; 23 de marzo de 1999, EDJ 1999/2574). El plagio resulta muy claro cuando existe una identidad entre la primera obra original y la segunda, a la que se imputa esta infracción de los derechos de propiedad intelectual del autor de la primera. Pero también se da en los casos en que, como apunta la referida jurisprudencia, no existe propiamente una absoluta identidad sino una "total similitud", encubierta con "ardides y ropajes que la disfrazan". Y esta similitud "ha de referirse a las coincidencias estructurales básicas y fundamentales y no a las accesorias, añadidas, superpuestas o modificaciones no transcendentales".

16 BÁez Jiménez. “El plagio: especial referencia a la obra cinematográfica”, cit., pp. 113 ss.

17 Ramírez Bacca, Renzo y Jiménez Patiño, Hernán David. "Plagio y auto-plagio: una reflexión”, HistoreLo. Revista de Historia Regional y Local, vol. 8, n. ${ }^{\circ}$ 16, 2016 , pp. 271-284, disponible en: https://revistas.unal.edu.co/index.php/historelo/article/view/56075 [consultado el 8 de septiembre de 2017].

18 Spinak, Ernesto. "Ética editorial y el problema del plagio", en Scielo en Perspectiva, 2013, disponible en: http://blog.scielo.org/es/2013/10/02/etica-editorial-y-el-problema-del-plagio/ [consultado el 10 de septiembre de 2017].

19 Disponible en: http://www.poderjudicial.es/search/contenidos.action?action=contentpdf $\&$ databasematch $=\mathrm{AN} \&$ reference $=6334371 \&$ links $=\% 22 \% 20$ constituye $\% 20$ un $\% 20$ acto $\% 20$ de $\% 20$ infracci $\%$ C $3 \%$ B 3n $\% 20$ de $\% 20$ los $\% 20$ derechos $\% 20$ de $\% 20$ explotaci $\%$ C 3 \% B 3 n $\% 20$ y $\% 2$ C $\% 20$ m\%C3\%A1s\%20espec\%C3\%ADficamente $\% 2 C \% 20$ de $\% 20$ reproducci\%C3\%B3n\%20del\%20autor\%20 de\%20la\%20obra\%20afectada\&optimize=20120416\&publicinterface=true [consultado el 10 de septiembre de 2017]. 
También indica la referida sentencia que el plagio tiene una acepción negativa que debe ser tenida en cuenta:

Junto a esta delimitación positiva de la acepción de plagio, existe otra negativa. Esa misma jurisprudencia antes citada explicita los casos en que no existe plagio: de una parte, por no haber confusión "con todo aquello que es común e integra el acervo cultural generalizado o con los datos que las ciencias aportan para el acceso y conocimiento por todos" (sTS 28 de enero de 1995, EDJ 1995/361); y de otra porque el contenido de las obras "está anticipado y al alcance de todos", como son los datos que constan "en registros fiscales, laborales, mercantiles o en las guías publicadas por Telefónica" (sTs 17 octubre 1997, EDJ 1997/7670). Esta doctrina jurisprudencial concluye que si en estos supuestos no existe plagio es porque, en el contenido respecto de lo que se denuncia la identidad, falta "creatividad y originalidad".

Ahora bien, el derecho de cita está contemplado en el artículo 32.1 TRLPI, que indica:

Es lícita la inclusión en una obra propia de fragmentos de otras ajenas de naturaleza escrita, sonora o audiovisual, así como la de obras aisladas de carácter plástico o fotográfico figurativo, siempre que se trate de obras ya divulgadas y su inclusión se realice a título de cita o para su análisis, comentario o juicio crítico. Tal utilización sólo podrá realizarse con fines docentes o de investigación, en la medida justificada por el fin de esa incorporación e indicando la fuente y el nombre del autor de la obra utilizada.

Y, respecto de ello, la analizada SAP señala:

La expresa incorporación de esta excepción del derecho de cita, respecto de la reproducción de fragmentos de obras ajenas, presupone que dicha "inclusión en una obra propia de fragmentos de otras ajenas" constituye un acto de infracción de los derechos de explotación y, más específicamente, de reproducción del autor de la obra afectada.

\section{[...]}

... aunque la demandada ha tomado muchas ideas y referencias de la obra de la actora, sin citarla como debiera desde el punto de vista académico porque fue la que, cuando menos, le puso en la pista de los documentos históricos de los que la actora sacó la información, que son los que con frecuencia cita directamente la demandada, ello no constituye propiamente un plagio desde el punto de vista jurídico, pues no se ha reproducido parcialmente la obra de la actora, sino que se han tomado de ella las principales referencias e ideas. 
En cuanto a la penalización del plagio, debemos indicar que el Código Penal lo tipifica como delito contra la propiedad intelectual ${ }^{20}$, en su artículo 270.1 que dispone:

1. Será castigado con la pena de prisión de seis meses a cuatro años y multa de doce a veinticuatro meses el que, con ánimo de obtener un beneficio económico directo o indirecto y en perjuicio de tercero, reproduzca, plagie, distribuya, comunique públicamente o de cualquier otro modo explote económicamente, en todo o en parte, una obra o prestación literaria, artística o científica, o su transformación, interpretación o ejecución artística fijada en cualquier tipo de soporte o comunicada a través de cualquier medio, sin la autorización de los titulares de los correspondientes derechos de propiedad intelectual o de sus cesionarios.

Respecto de los elementos que intervienen, según ha precisado la jurisprudencia que hemos analizado, en particular la SAP Donostia-San Sebastián, de 15 de junio de $2012^{[21]}$, ponente: D. Jorge Juan Hoyos Moreno, es de señalar:

El delito contra la propiedad intelectual así regulado requiere, para que quede cumplidamente acreditada su consumación, de la concurrencia de los siguientes elementos: A) Una acción de reproducción, plagio, distribución o comunicación pública de obra literaria, artística o científica, o de su transformación, interpretación o ejecución de las mismas en cualquier tipo de soporte o su comunicación por cualquier medio, o su importación o almacenamiento. B) Carencia de autorización para cualquier clase de esas actividades concedida por los titulares de los correspondientes derechos de propiedad intelectual. C) Dolo, como conocimiento de los elementos objetivos del tipo y voluntad de realizar la conducta típica. D) Y ánimo de lucro como elemento que en el actual código configura el tipo básico (anteriormente cualificaba el delito) en su vertiente subjetiva y delimita, junto con el perjuicio de tercero, el objeto de protección penal, que ahora se circunscribe al aspecto patrimonial de los derechos de propiedad intelectual. Debe, en consecuencia, acreditarse cumplidamente en cada caso concreto la concurrencia de todos los elementos que integran el delito objeto de acusación, tanto los objetivos como los subjetivos, y singularmente y para lo que aquí ahora nos interesa, debe acreditarse que la obra literaria, artística o científica en cuestión ha sido reproducida, plagiada, distribuida o comunicada públicamente sin la autorización de los titulares de los correspondientes derechos de la propiedad intelectual o de sus cesionarios.

20 Más ampliamente, Iglesias Río, Miguel Ángel. "El plagio en el marco de los delitos contra la propiedad intelectual", en La propiedad intelectual en las universidades públicas: titularidad, gestión y transferencia, Raquel de Román Pérez (coord.), Granada, Comares, 2016, pp. 223-253.

21 Disponible en: http://www.poderjudicial.es/search/contenidos.action?action=contentpdf\&data basematch $=$ AN \& reference $=7088847 \&$ links $=\&$ optimize $=20140605 \&$ publicinterface $=$ true $\quad[$ consultado el 10 de septiembre de 2017]. 


\section{EL PLAGio EN LA ObRa ARTística. EL CASO DE LA ObRA AUdiOViSUAL}

El plagio o copia, también entendido como hurto de la obra, se ha dado a lo largo de la literatura y bellas artes en general, en definitiva, en la obra entendida como creación artística, literaria y científica. Como afirma la doctrina ${ }^{22}$, esta práctica la encontramos como una de las formas de imitación para la adquisición de un oficio:

En literatura y también durante siglos, se ha admitido tácitamente que una de las formas de adquirir oficio es la imitación, incluso renglón por renglón, como cuando en el siglo XVIII aparecieron himnos pindáricos y odas horácicas. En nuestra lengua, Fray Luis de León ha de haber azorado a sus contemporáneos cuando escribió: "Tomar de lo ajeno es ley de procreación". Luego don Cristóbal del Castillejo sería lapidario: "Copiar o morir". Lógicamente, debe tratarse solo de franjas, aunque no se aclaran longitudes cuando Cervantes escribe: "Es lo que hacen igual todos los hombres mortales para vivir y prosperar: cogen los alimentos de más fácil asimilación y los incorporan a su sangre, cogen lo que les conviene y lo hacen suyo".

\section{$[\ldots]$}

Es una verdad como una casa que con el actual auge de la técnica paródica, los creadores de las expresiones artísticas han hallado una veta que parece inagotable. Cada vez con más claridad los creadores trabajan con alguna obra anterior o con fragmentos. Bien pueden ser pasajes, trazos, notas musicales, metros de película... En un espectro que se mueve entre el tributo (¿de vasallaje?) y el guiño cordial, sin desestimar momentos de sincera basura.

En el caso de una obra audiovisual es preciso considerar que tiene una serie de características que la distinguen de una obra literaria, científica o técnica. La obra audiovisual como obra artística tiene un formato específico que en sí mismo no es lo que se considera protegido, siéndolo la obra que lo contiene. La SAP Madrid de 17 de septiembre de 2015, ponente: D. Ángel Galgo $\mathrm{Peco}^{23}$, aporta algunas indicaciones interesantes acerca de la originalidad de la obra, en este caso una teleserie entendida como obra audiovisual.

La mencionada sentencia parte de la consideración de que el formato, entendido como una receta o manual de instrucciones para la producción de una obra, no es la obra en sí, sino el continente de la misma. No es adecuado acudir al objeto, tema o concepto que se representa en la obra, ya que es el artículo 10.1 TRLPI el

22 García, José Luis. “¿La imitación o el arte de copiar?”, Chasqui: Revista Latinoamericana de Comunicación, n. ${ }^{\circ}$ 62, 1998, pp. 79-80, disponible en: http://www.revistachasqui. org/index.php/chasqui/article/view/1207 [consultado el 10 de septiembre de 2017].

23 Disponible en: http://www.poderjudicial.es/search/contenidos.action?action=contentpdf\&datab asematch $=$ AN\&reference $=7505677 \&$ links $=\% 22$ plagio $\% 22 \% 20$ Y $\% 20 \% 22$ espect $\%$ C $3 \%$ A 1 culo $\% 22 \&$ op timize $=20151029 \&$ publicinterface $=$ true [consultado el 10 de septiembre de 2017]. 
que indica que es la creación, como objeto de protección, tiene que tener una forma externa, que sea perceptible, y va mucho más allá de la mera diferenciación entre tangible e intangible.

La sentencia precisa:

... es el producto concreto del proceso creativo, identificado por la específica conformación con la que se exterioriza, lo que constituye objeto de protección por la propiedad intelectual. Es la obra como tal, entendida conforme a los parámetros expuestos, y no las ideas, conocimientos o la información expresada a través de ella, lo que es susceptible de propiedad intelectual (ssts de 26 de octubre de 1992, 7 de junio de 1995 y 26 de noviembre de 2003).

La originalidad se asocia más a la consideración como singular de una determinada obra, y que pueda ser diferenciada de otras obras ya existentes, teniendo en cuenta la impresión que produce en quien percibe la misma. Debe incorporar una impronta peculiar que la haga distinta de las demás, y asociada a una creatividad, de ahí la postura del Tribunal Supremo, en sentencias de 24 de junio de $2004^{\text {[24] }}$ y 5 de abril de $2011^{[25]}$, de entender creación original como originalidad creativa, o bien aportación creativa que reúna suficiente originalidad, como indica en la sentencia de 18 de diciembre de $2012^{[26]}$, o en la de 25 de junio de $2013^{[27]}$, en la que se señala que originalidad y altura creativa son necesarias para que la obra sea protegida por la propiedad intelectual.

\section{EL PLAGIO EN LA OBRA MUSICAL: ESTUDIO DE DISTINTOS CASOS}

En este apartado se analizan dos casos de obras musicales en los que se plantea si existe o no originalidad y, por tanto, si se ha producido un plagio de otra obra preexistente.

La originalidad en el caso de la obra musical, ha precisado la doctrina ${ }^{28}$, combina tres elementos fundamentales: armonía, melodía y ritmo, señalando además que se puede dar la originalidad incluso en el caso de composiciones muy breves. El

24 Disponible en: http://www.poderjudicial.es/search/contenidos.action?action=contentpdf\&d atabasematch $=$ TS \& reference $=2121591 \&$ links $=$ intelectual $\&$ optimize $=20040821 \&$ publicinterface $=$ true [consultado el 17 de abril de 2018].

25 Disponible en: http://www.poderjudicial.es/search/contenidos.action?action=contentpdf\&d atabasematch $=$ TS $\&$ reference $=5966438 \&$ links $=$ intelectual $\&$ optimize $=20110519 \&$ publicinterface $=$ true [consultado el 17 de abril de 2018].

26 Disponible en: http://www.poderjudicial.es/search/contenidos.action?action=contentpdf\&d atabasematch $=$ TS \& reference $=6610914 \&$ links $=$ in telectual $\&$ optimize $=20130125 \&$ publicinterface $=$ true [consultado el 17 de abril de 2018].

27 Disponible en: http://www.poderjudicial.es/search/contenidos.action?action=contentpdf\&d atabasematch $=$ TS \& reference $=6810924 \&$ links $=$ in telectual $\&$ optimize $=20130729 \&$ publicinterface $=$ true [consultado el 17 de abril de 2018].

28 García Sedano. "Análisis del criterio de originalidad para la tutela de la obra en el contexto de la Ley de Propiedad Intelectual”, cit., p. 259. 
primer caso objeto de estudio es la obra musical Me gustas tú. El litigio se centra, por un lado, en la infracción de derechos patrimoniales exclusivos de reproducción y comunicación pública; y por otro, en el derecho moral de autor con respecto a la obra musical del título indicado, cuyo autor era D. D. y licenciataria de los derechos de explotación la sociedad francesa R.B., por razón de la utilización, de forma parcial y alterada de la misma en un anuncio o spot publicitario para promocionar un diario de prensa gratuito.

La SAP Barcelona de 21 de junio de 2011, ponente: D. Luis Garrido Espa, se pronunció en el siguiente sentido:

Por ello, además de o junto a la comparación desde el punto de vista objetivo y técnico de los distintos elementos que componen la obra musical (melodía, armonía, ritmo, tonalidad, carácter, tímbrica y en su caso la letra), debiera valorarse la medida en que el consumidor medio, al que no debe atribuirse conocimientos técnico-musicales, pese a captar diferencias objetivas entre una y otra obra, pueda destacar éstas sobre las semejanzas, o a la inversa, en orden a distinguir una obra de otra, a atribuir originalidad a la posterior respecto de la anterior, a determinar en suma si la posterior es una copia sustancial de la anterior o no lo es. Y en ese juicio de valor influyen sin duda factores como la evocación o el recuerdo.

Así, la sAP referida indica que la fallada por el juzgado de primera instancia advierte que debe ser comparada la obra musical cuya autoría demanda el autor Sr. D. con la contenida en los spots publicitarios del diario en cuestión, estableciendo si puede inducir a confusión, recuerda o tiene relación con la primera.

De tal forma que debe constatarse si no existe una identidad absoluta entre las melodías o el ritmo de las canciones, de forma que la escucha de las mismas produce el recuerdo o evocación, y se concluye que la obra del Sr. D. sí que ha sido alterada en la versión del spot, y de ahí la infracción de derechos de propiedad intelectual. Es precisamente la consideración de la evocación o recuerdo de un argumento lo que considera la jurisprudencia para pronunciarse sobre este caso.

Es justamente esto lo que debemos determinar para considerar o no una obra como original. Es decir, si el criterio de evocación o recuerdo debe ser idóneo para determinar la originalidad de una obra, o por el contrario no afecta a la originalidad entendida como creación con aportación del autor, aunque recuerde una determinada obra o la evoque.

La sentencia utiliza los siguientes argumentos:

a) Evocación o recuerdo. Teniendo en cuenta el denominado test del oyente medio y la percepción del público, la apreciación del plagio, indica la sentencia, requiere comparar si la semejanza de las dos obras (las composiciones musicales) en conflicto es sustancial, considerando la originalidad de la obra que se litiga frente a la preexistente. Hay que determinar si basta con constatar diferencias objetivas referidas a los elementos que componen la obra musical, o si es posible apreciarla, 
teniendo en cuenta otros parámetros, como la evocación o recuerdo que la obra preexistente produce en la obra litigiosa respecto a la percepción del oyente, como destinatario-consumidor de la misma.

La sentencia indica que es más razonable, respecto de la obra de música ligera, como en este caso, la conjugación o combinación de unos y otros criterios de los indicados, para determinar si existe una semejanza sustancial que dé lugar a considerar que hay una reproducción alterada de la obra ajena o plagio. Para ello, el elemento relevante de apreciación radica en la impresión que la obra produce en el círculo del destinatario, en la percepción del público como criterio subjetivo, y que debe ser identificado con la figura ficticia del oyente medio.

Es decir, la sentencia no se refiere a un oyente especializado para determinar si hay o no originalidad, sino a un público habitual de ese tipo de composición, que subjetivamente determine la identidad y similitud entre las dos obras controvertidas. El oyente medio es considerado por la sentencia el público atento y perspicaz que puede percibir la obra como una composición musical original y diferente en los aspectos expresivos fundamentales respecto de la obra anterior, o en atención a factores de percepción subjetiva como es la evocación, la relación o el recuerdo de la obra anterior.

Se debe atender a si es percibida como una copia sustancial más o menos encubierta, precisa la sentencia, por ser accesorias o irrelevantes las diferencias. Sigue insistiendo el tribunal en que además o junto a la comparación objetiva y técnica de los elementos que conforman la obra musical, como lo son la melodía, la armonía, el ritmo, la tonalidad, el carácter, la tímbrica y la letra, debe ser valorada la forma en que el consumidor medio, que no tiene conocimientos técnicos-musicales, a pesar de captar diferencias objetivas entre las dos obras, puede también apreciar las semejanzas. Y a la inversa, si es capaz de distinguir una obra de la otra, en orden a apreciar que es original respecto a la que se considera plagiada, y a través de esa apreciación determinar si es o no una copia sustancial.

El juicio de valor que recae sobre la evocación o recuerdo puede ser un "arma de doble filo", consideramos desde nuestro punto de vista, ya que muchas veces cuando escuchamos una música puede recordarnos a otra, y no necesariamente tiene que existir en esos casos plagio, ya que por diversos factores, por ejemplo, notas o estribillos repetidos, puede el subconsciente realizar una asociación de recuerdos que pueden o no ser ciertos. Otro aporte lo podemos encontrar en el caso de las nanas o canciones infantiles, que tienen una composición muy similar e inmediatamente las asociamos con el sueño del niño, a través de determinadas notas (como en el clásico "duérmete niño, duérmete ya"). Postulamos que debe realizarse un análisis riguroso en el caso de la obra musical, respecto del ritmo, las notas, el tono y, por supuesto, la letra), para determinar o no la existencia de plagio, y ello es especialmente relevante en el caso de los arreglos musicales, que veremos en un apartado ulterior de este trabajo. 
b) Falta de distinguibilidad, referido a determinar el grado de apropiación de la obra ajena.

Uno de los aspectos más complejos es determinar el grado de apropiación de la obra ajena. Desde luego, como advierte la sentencia, la prueba pericial se convierte en un instrumento clave para realizar un examen comparativo objetivo respecto a los elementos que componen una obra musical (compás, tonalidad, modalidad, carácter, tiempo, ritmo, métrica, tímbrica, armonía, melodía y letra).

La sAP Barcelona de 9 de enero de 2004 ${ }^{[29]}$, ponente: D. José Ramón Ferrándiz Gabriel, indicó respecto de las obras musicales que es el sonido el elemento expresivo básico,

... cuya estructura depende de la altura, la duración, la intensidad y el timbre, y cuya exteriorización permite distinguir entre melodía (composición en que se desarrolla una idea musical, simple o compuesta, con independencia de su acompañamiento), armonía (combinación de sonidos simultáneos diferentes, pero acordes) y ritmo (resultado de las relaciones de tiempo entre los sonidos). Esos elementos, junto con la letra, en especial en algunas obras destinadas al baile, permiten la identificación del objeto protegido y deslindar la reproducción de la transformación.

En el caso que nos ocupa, el de la obra musical, la letra también constituiría, junto con la melodía, un parámetro para apreciar si ha habido o no plagio, y para poder determinar la semejanza sustancial o no entre las obras controvertidas.

Como indica la sAP Barcelona de 21 de junio de 2011, los dictámenes que se aportan son los que destacan las diferencias objetivas entre las dos obras, y aprecian diferencias de estilo, ritmo, armonía y tonalidad, que derivan en una línea melódica diferente, con un efecto musical distinto, considerándose dos obras diferentes, sin que la expresión de "me gustas tú" pueda alterar la consideración de entender las obras como independientes.

Otro de los elementos probatorios en este caso se encuentra en el dictamen del ingeniero de sonido que indica la ausencia de coincidencias en duración y sonoridad de la base instrumental y vocal. En efecto, en las imágenes gráficas del editor digital referidas a los fragmentos de las dos obras comparadas se aprecian diferencias visuales de tiempo y de forma de la onda acústica.

El recurso de la evocación que menciona el tribunal puede ser apoyado por un dictamen, pero la evocación no invalida la originalidad, a nuestro juicio, siempre y cuando la obra sea lo suficientemente distinta para apreciar la impronta del autor de la obra evocante. Vamos a precisarlo un poco más.

La razón radica en el análisis pericial que se realice a través del dictamen aportado por peritos, que arroje una diferenciación de las obras, pese a la evocación

29 Disponible en: http://www.poderjudicial.es/search/contenidos.action?action=contentpdf\&dat abasematch $=$ AN \&reference $=2675852 \&$ links $=$ melod $\% C 3 \% A D a \&$ optimize $=20040228 \&$ publicinterface $=$ true [consultado el 18 de abril de 2018]. 
referida. Si se aprecian no identidades sino similitudes, y la tonalidad y modalidad es diferente, y el ritmo, la métrica y la tímbrica son similares, pero existen notables diferencias, y hay cercanía, pero no paralelismo al comparar los fragmentos, siendo en el caso de la presente obra el fragmento más similar el que coincide con la letra "me gustas tú", no se determina que sean idénticos y la entidad musical está diferenciada en muchos aspectos. Pese a la evocación del fragmento de la obra anterior, las obras no son idénticas en los objetivos estructurales, por lo que el efecto musical es distinto y las obras se pueden diferenciar una de la otra.

Además, también influye la percepción de una letra ("me gustas tú") que es una expresión que se utiliza comúnmente en la música ligera, como habíamos indicado anteriormente, en las canciones infantiles o nanas, la expresión "duérmete niño", y tendría que determinarse hasta qué punto la evocación o recuerdo de una obra anterior a través del empleo de una expresión habitual puede ser plagio y la obra no es considerada como original, ya que, evidentemente, las expresiones habituales no puede considerarse que inhiban la originalidad de una obra, pues entonces no podrían emplearse sino en una ocasión. Son muchos más los factores, como hemos indicado, que hacen una obra original; en el caso de la obra musical, los parámetros referidos de conjunto de melodía, notas, timbre, tono, etc., y siempre que sea posible distinguir las dos obras como entidades diferentes y distintas de la anterior.

La evocación del público es una referencia de carácter subjetivo, ya que también influirá si conoce o no la obra preexistente, para determinar si la nueva se la evoca o no; por tanto, no es unánime en todas las personas, y también influirá si es un colectivo especializado o no; de ahí que el tribunal se refiera al denominado oyente medio, con el llamado "test del oyente medio", para que se pueda probar la falta de distinción entre las obras y el grado de apropiación de la ajena que determine la falta de originalidad. Precisamente por todos estos argumentos se desestima la demanda.

En el segundo caso se trataba del autor de la canción Se acabaron tus agallas, quien interpuso juicio contra la discográfica S. M. E.s. S.A., editora esta de un disco del dúo A.M. donde se recoge la canción El amor que, afirmaba, era plagio de la suya.

La SAP Madrid de 30 de junio de $2005^{[30]}$, ponente: Victoriano Jesús Navarro Castillo, desestimó el recurso y confirmó la sentencia de instancia en la que se absolvía a la discográfica.

En este caso el tribunal determina que no existe plagio. Se aporta dictamen de especialista que aprecia los siguientes elementos:

a) En el caso, las armonías que se utilizan

... en estas composiciones, así como el orden interválico de las melodías, se ajustan plenamente a un tipo muy generalizado y de uso común en la llamada música ligera, a

30 Disponible en: http://www.poderjudicial.es/search/contenidos.action?action=contentpdf\&dat abasematch $=$ AN\&reference $=1118775 \&$ links $=$ melod $\% C 3 \% A D a \& o p t i m i z e=20051124 \&$ publicinterface $=$ true [consultado el 18 de abril de 2018]. 
la que corresponden las citadas composiciones. La simplicidad de recursos compositivos melódicos y armónicos limita las posibilidades de originalidad, permitiendo constantes similitudes entre las melodías, temas, etc., si bien no necesariamente en su totalidad, que resulta más difícil por razones obvias, pero sí con mayor frecuencia entre algunas partes, arranques melódicos (como es el caso que nos ocupa), secuencias armónicas, elementos rítmicos concretos, etc.

b) El tempo utilizado en las dos melodías es diferente, y ello determina el carácter y estilo de las dos canciones.

c) Que exista un parecido de una pequeña secuencia melódica no determina que se pueda considerar como plagio. Además, apunta la sentencia que "[d]e no ser así, la mitad del repertorio de la música comercial sería plagio de la otra mitad".

d) Falta de coincidencias estructurales básicas y fundamentales que denoten apropiación y aprovechamiento de una labor creativa y esfuerzo intelectual del autor.

e) Diferencias en las tonalidades de las composiciones. Existen distintos grados tonales y no las mismas notas. Sí que se observa una coincidencia en 16 notas, pero el pasaje es una progresión melódica y en este caso, al ser las frases simétricas, es suficiente con las primeras 8 notas, ya que las restantes 8 son una natural consecuencia derivada del arranque.

f) Hay un tempo mucho más rápido en una obra que en otra, de ahí que la coincidencia de compases es menor que si el tempo fuera más lento.

g) La naturaleza sincopada de las melodías no es distinta, lo que las hace diferentes es el tempo y el compás; suenan parecidas, pero no iguales.

h) La observancia de similitud entre ambos pasajes melódicos se debe a la utilización de giros habituales en este tipo de música y la influencia de un tema en otro puede haberse realizado de forma inconsciente.

i) En este caso la evocación o recuerdo de una obra respecto de la otra constituye un recurso frecuente, pero hay una diferencia sustancial entre las dos composiciones, y la coincidencia de notas puede ser causal y no premeditada.

Sobre la base de este dictamen, que resulta fundamental en la resolución del caso, el tribunal en la sentencia precisa algunas cuestiones respecto a la originalidad de la obra, luego de solicitar una ampliación del dictamen, dentro de la prueba practicada, en donde el perito contesta a una serie de cuestiones que interesa resaltar:

1. Respecto a si la secuencia melódica sirve para identificar la originalidad de una composición musical, se indica que los motivos que las integran son piezas fundamentales para la realización de la composición y su distinción, pero no es el único elemento que identifica a la composición. Una misma secuencia melódica o interválica puede estar modificada por el comportamiento armónico, rítmico y el tempo que se utilice.

2. Sobre si una obra musical que se interpreta con distinto tempo, armonía o ritmo puede perder la originalidad por dicha razón, el perito considera que serían composiciones diferentes, a pesar de que la idea temática inicial fuera igual. En 
el caso de las obras en cuestión, no es una coincidencia general, sino específica, y queda afectado solo un pasaje corto y concreto.

3. Hay un mayor contraste entre las dos obras, y una diferencia entre el tempo que definen dos caracteres distintos pero no opuestos, siendo una obra más lírica y la otra más rítmica.

4. La existencia de un parecido de una breve secuencia melódica no es suficiente para considerar que existe plagio. No se considera que una obra sea derivada de la otra.

En el caso de la obra musical resulta fundamental, como hemos visto en los dos casos analizados, la aportación de los dictámenes de expertos para determinar si existe o no el plagio ${ }^{31}$.

Los dos casos analizados son sustancialmente diferentes, pero tienen en común la referencia a la evocación o recuerdo de la melodía, que, como hemos indicado, no es suficiente para la determinación de si es la obra es original o no, o si se ha producido o no plagio de una respecto de la otra.

\section{EL PLAGIO, LOS ARREGLOS MUSICALES U OBRA DERIVADA: DISTINCIÓN}

Cuestión distinta es la de los casos de la denominada obra derivada y obra transformada, así como de los denominados "arreglos musicales" y su diferenciación del plagio ${ }^{32}$.

Se pueden producir distintas situaciones que se pueden considerar como obra derivada $^{33}$ :

a) Obra derivada en la que se han realizado arreglos musicales o variaciones.

b) Obra derivada en la que se han realizado instrumentaciones u orquestaciones.

Hay que tener en cuenta si la obra que se ha adaptado o arreglado pertenece al dominio público, caso en el cual se tendrá la totalidad de los derechos, pero se precisará la cita de la obra; en el caso de que la obra que se adapta o arregla esté protegida, se necesitará documento escrito de autorización del titular de los derechos.

31 Como pone de relieve también Báez Jiménez, Diana Carolina. "El plagio. Especial referencia a la obra cinematográfica”, Revista La Propiedad Inmaterial, n. o 19, 2015 , pp. 113-166, disponible en: http://revistas.uexternado.edu.co/index.php/propin/article/view/4162 [consultado el 6 de septiembre de 2017], en el caso de la obra cinematográfica no se utiliza el equivalente del test del oyente medio, sino que se han utilizado los siguientes métodos sistemáticos para comparar obras de diferentes géneros y evaluar su similitud:

a) En Nichols v. Universal Pictures Corp. 45 F.2d 119 (2d Cir.) (1930) se utilizó el "Abstraction Test" o "Test de abstracción".

b) En Roth Greeting Cards v. United Card Company, 429 F. 2d 1106 (9th Cir. 1970) se aplicó el "The Total Concept and Feel Test" o "Test del concepto y de sensación total".

c) En Sid \& Marty Krofft Television Productions., Inc. v. McDonald's Corp. 562 F.2d

1157 (9th Cir. 1977) se empleó el "Extrinsic Test-Instrinsic Test" o "Test extrínsecoTest intrínseco".

32 Galacho Aвоlafio. La obra derivada musical. Entre el plagio y los derechos de autor, cit., p. 246.

33 Castellote, Ruth. “Algunas cuestiones sobre los arreglos musicales”, Blog, 2004, disponible en: https://ruthcastellote.wordpress.com/2014/09/03/algunas-cuestiones-sobre-los-arreglosmusicales/ [consultado el 8 de septiembre de 2017]. 
En todo caso y en ambos supuestos (dominio público y otra protegida) será precisa la cita de la obra preexistente.

Para la determinación del plagio habría que aplicar lo indicado anteriormente respecto de la obra musical, considerando que si existe suficiente diferenciación entre las dos obras se mantiene el criterio de la originalidad. En este caso tenemos que tener en cuenta que la obra derivada se produce mediante la intervención de la obra preexistente, y que en ningún caso se considera por sí misma como plagio, sino como una transformación de la obra primitiva.

\section{CONCLUSIONES}

Deslindar entre lo que es original y lo que es copia, imitación, reinvención, falsificación, apropiación, muchas veces no resulta tarea fácil ${ }^{34}$. La sutileza del plagiario no es exclusiva de la obra musical, sino que también se produce en otro tipo de obras ${ }^{35}$.

La jurisprudencia se ha pronunciado sobre distintos casos de plagio de la obra musical, indicando de forma específica los requisitos, y se ha manifestado de forma clara sobre los mismos.

En este sentido, el argumento de evocación o recuerdo de una obra no constituye un elemento único para tener en cuenta, ya que hay que atender a otros elementos, como el timbre, las notas, el ritmo, el compás, la tonalidad, la modalidad, el carácter, el tiempo, la métrica, la armonía, la melodía y la letra, que determinan la originalidad de la obra. En el caso de obras musicales con letra, la utilización de frases conocidas puede plantear algunas cuestiones respecto a la originalidad, como en los casos analizados en el presente trabajo, pero hay que deslindar el recuerdo de una obra ya escuchada de la utilización de frases que pueden resultar habituales en la práctica, y que determinarían que la mayoría de obras pudieran ser plagio de otras ya existente.

34 Rosen, Charles. "Influencia: inspiración y plagio", Quodlibet: Revista de Especialización Musical, n.o 13, 1999, pp. 13-30; Klenz, William. "El opus 38 de Brahms: ¿piratería, pillaje, plagio o parodia?”, Quodlibet: Revista de Especialización Musical, n.o 17 , 2000, pp. 3-16. Como indican Timal López, Sandra y Sánchez Espinosa, Francisco. "El plagio en el contexto del derecho de autor", Tla-melaua: Revista de Ciencias Sociales, vol. 11, n. ${ }^{\circ} 42$, 2017, p. 52, disponible en: http://www.apps.buap.mx/ojs3/index.php/tlamelaua/ article/view/281/229 [consultado el 19 de abril de 2018]: "En la época greco-romana, se hablaba de la imitación de obras y de la emulación de modelos clásicos. Se entendía por 'imitar' el acto de copiar, pues el aprendiz sólo podía adquirir conocimiento copiando las ideas, ejemplos y enseñanzas de sus maestros. Un aprendiz, al plasmar en un texto la idea de su maestro, estaba generando y transmitiendo conocimiento, de modo que el hecho de 'imitar' a su profesor no podía ser una mala práctica. Por 'emular' se entendía también el acto de imitar; pero se usaba en las obras teatrales y representaciones artísticas, no en textos. De modo que en esa época imitar y emular a los autores originales eran buenas prácticas".

35 López Farjeat. "Falsificación, apropiación y plagio. Reflexiones a partir de la transfiguración del lugar común”, cit., pp. 58 ss. Cfr. también López Rodríguez, FerNANDO. "Intertextualidad dramática y derechos de autor", RDUNED. Revista de Derecho UNED, n. ${ }^{\circ}$ 20, 2017, pp. 351-372, disponible en: http://revistas.uned.es/index.php/RDUNED/ article/view/19491/16327 [consultado el 19 de abril de 2018]. 
En los casos de arreglos o adaptaciones no se pueden establecer reglas generales absolutas, ya que hay que atender a las situaciones de la obra derivada según los arreglos o adaptación de la obra en sí. En el presente trabajo nos hemos ocupado de la música en relación con la imagen, pero también existen casos de plagio y discusiones sobre la originalidad en el ámbito de la videodanza ${ }^{36}$.

Cuestión distinta es la de los casos de fraude, que hay que diferenciar del plagio. Entre tantos casos famosos en que se ha discutido de eventual existencia de fraude cabe mencionar los de Milli Vanilli, Technotronic, Boney M, C+C Music Factory ${ }^{37}$ y Michael Jackson ${ }^{38}$. Estos han llegado a los medios de comunicación, $y$ en algunos de ellos ha resultado que quienes cantaban no eran los afamados artistas. Es esta una situación distinta del plagio, pero que constituye un fraude, como lo es el plagio ${ }^{39}$.

En definitiva, como indica Schneider ${ }^{40}$ : "Hay dos maneras de decir que el plagio no es un problema: no verlo por ninguna parte, o afirmar que está en todos lados” ${ }^{1}$.

\section{REFERENCIAS}

Arévalo Molina, Julio. "Qué es el plagio y cómo detectarlo", en Desiderata, n. ${ }^{\circ}$ 6, 2017, pp. 24-26, disponible en: http://desiderataonline.com/ [consultado el 6 de septiembre de 2017].

Báez Jiménez, Diana Carolina. "El plagio: especial referencia a la obra cinematográfica”, Revista La Propiedad Inmaterial, n.o 19, 2015, pp. 113-166, disponible en: http://revistas.uexternado.edu.co/index.php/propin/article/ view/4162 [consultado el 6 de septiembre de 2017].

36 Ramón Fernández. "El concepto de la originalidad en la videodanza: una cuestión de pasos e imagen”, cit., pp. 131 ss.

37 Landeira, Luigi. "Los 20 timos más flagrantes de la historia del pop. Vocalistas que no cantan, músicos que no tocan, compositores que copian, mánagers que cogen todo el dinero y corren... Repasamos los mayores fraudes", El País. 13 de abril de 2016, disponible en: https://elpais.com/elpais/2016/03/10/icon/1457610637_611325.html [consultado el 10 de septiembre de 2017].

38 "Paris Jackson: mi padre no canta ninguna canción de ese álbum”. Búsquese en YouTube: Jason Malachi, “¡Es él!”. La conversación fue grabada y se filtró a internet. Malachi reveló la verdad en su Facebook: "Chicos, creo que es hora de confesar. Era yo quien cantaba Breaking News, Keep Your Head Up, Monster y Stay. Yo tenía un acuerdo con la compañía discográfica, pero ahora el gato está fuera de la bolsa. Perdón a todos mis fans, y a los fans de Michael Jackson". Tomado de: https://elpais.com/elpais/2016/03/10/ icon/1457610637_611325.html [consultado el 10 de septiembre de 2017].

39 Cfr. Escudero Musolas, Antonio. “Ritmo noticias. 'Love Story', ¿un plagio?”, en Ritmo, vol. 41, n.o 412, 1971, p. 2; Cogo, Alessandro. "Il plagio d'opera musicale tra identità 'del testo e diversità' del contesto", Giurisprudenza italiana, n. ${ }^{\circ} 1,2016$, pp. 109-111.

40 Schneider, Michel. Voleurs de mots: essai sur le plagiat, la psychanalyse et la pen, Paris, Gallimard, 1985.

41 Nettel Díaz, Ana Laura. "Derecho de autor y plagio", en Alegatos, n. ${ }^{\circ}$ 83, enero/abril, 2013, pp. 135-152, disponible en: http://www.corteidh.or.cr/tablas/r32329.pdf [consultado el 8 de septiembre de 2017]. 
Castellote, Ruth. "Algunas cuestiones sobre los arreglos musicales", Blog, 2004, disponible en: https://ruthcastellote.wordpress.com/2014/09/03/algunas-cuestiones-sobre-los-arreglos-musicales/ [consultado el 8 de septiembre de 2017].

Cogo, Alessandro. "Il plagio d'opera musicale tra identità 'del testo e diversità' del contesto", en Giurisprudenza italiana, n. ${ }^{\circ}$ 1, 2016, pp. 109-111.

Escudero Musolas, Antonio. "Ritmo noticias. 'Love Story', ¿un plagio?”, en Ritmo, vol. 41, n.o 412, 1971, p. 2.

Fernández Sarasola, Ignacio. "Plagio científico y vulneración de derechos fundamentales", Teoría y Realidad Constitucional, n. ${ }^{\circ}$ 20, 2017, pp. 385-397, disponible en: http://revistas.uned.es/index.php/TRC/article/view/20923/17397 [consultado el 19 de abril de 2018].

Galacho Abolafio, Antonio Francisco. La obra derivada musical. Entre el plagio $y$ los derechos de autor, Pamplona, Aranzadi, 2014.

García, José Luis. “¿La imitación o el arte de copiar?”, Chasqui: Revista Latinoamericana de Comunicación, n. ${ }^{\circ}$ 62, 1998, pp. 79-80, disponible en: http:// www.revistachasqui.org/index.php/chasqui/article/view/1207 [consultado el 10 de septiembre de 2017].

García Sedano, Tania. "Análisis del criterio de originalidad para la tutela de la obra en el contexto de la Ley de Propiedad Intelectual", Anuario Jurídico y Económico Escurialense, n. ${ }^{\circ}$ 49, 2016, pp. 251-274, disponible en: http:// www.rcumariacristina.net:8080/ojs/index.php/AJeE/article/view/269/pdf [consultado el 19 de abril de 2018].

Guiralt Gomar, Carmen y Carratalá, Adolfo. "El plagio cinematográfico de Letty Lynton (1932) y su impacto en la industria fílmica estadounidense: análisis del proceso judicial y de su cobertura mediática”, en Observatorio (OBS), vol. 10, n.o 3, 2016, pp. 1-19, disponible en: http://obs.obercom.pt/index. php/obs/article/view/991 [consultado el 9 de septiembre de 2017].

Iglesias Río, Miguel Ángel. "El plagio en el marco de los delitos contra la propiedad intelectual", en La propiedad intelectual en las universidades públicas: titularidad, gestión y transferencia, RAQUel De RoMÁn PÉREZ (coord.), Granada, Comares, 2016, pp. 223-253.

Klenz, William. "El opus 38 de Brahms: ppiratería, pillaje, plagio o parodia?", Quodlibet: Revista de Especialización Musical, n. ${ }^{\circ}$ 17, 2000, pp. 3-16.

Landeira, Luigi. "Los 20 timos más flagrantes de la historia del pop. Vocalistas que no cantan, músicos que no tocan, compositores que copian, mánagers que cogen todo el dinero y corren... Repasamos los mayores fraudes", El País, 13 de abril de 2016, disponible en: https://elpais.com/elpais/2016/03/10/ icon/1457610637_611325.html [consultado el 10 de septiembre de 2017].

López Farjeat, Luis Xavier. "Falsificación, apropiación y plagio. Reflexiones a partir de la transfiguración del lugar común", en Páginas de Filosofía, vol. 16, n. ${ }^{\circ}$ 19, 2015, pp. 58-79, disponible en: http://revele.uncoma.edu.ar/htdoc/revele/ index.php/filosofia/article/view/979 [consultado el 10 de septiembre de 2017]. 
López Rodríguez, Fernando. "Intertextualidad dramática y derechos de autor", RDUNED. Revista de Derecho UNED, n. ${ }^{\circ} 20,2017$, pp. 351-372, disponible en: http://revistas.uned.es/index.php/RDUNED/article/view/19491/16327 [consultado el 19 de abril de 2018].

Nettel Díaz, Ana Laura. "Derecho de autor y plagio", Alegatos, n. ${ }^{\circ} 83$, eneroabril, 2013, pp. 135-152, disponible en: http://www.corteidh.or.cr/tablas/ r32329.pdf [consultado el 8 de septiembre de 2017].

Ramírez Bacca, Renzo y Jiménez Patiño, Hernán David. "Plagio y auto-plagio: una reflexión”, HiSTOReLo. Revista de Historia Regional y Local, vol. 8, n. ${ }^{\circ} 16$, 2016, pp. 271-284, disponible en: https://revistas.unal.edu.co/index.php/ historelo/article/view/56075 [consultado el 8 de septiembre de 2017].

Ramón Fernández, Francisca. "La protección de los derechos de autor de las fotografías y la prestación del consentimiento", Revista Aranzadi de Derecho y Nuevas Tecnologías, n. ${ }^{\circ}$ 31, 2013, pp. 47-74.

Ramón Fernández, Francisca. "La redefinición de las excepciones en materia de propiedad intelectual. Derecho de cita, plagio e internet", en Libertad de expresión e información en internet. Amenazas y protección de los derechos personales, Lorenzo Cotino Hueso y Loreto Corredoira Alfonso (coords.), Madrid, Centro de Estudios Políticos y Constitucionales, 2013, pp. 233-258.

RAmÓn FernándeZ, Francisca. "La obra cinematográfica y audiovisual: fronteras reales e imaginarias en el ámbito jurídico", en Fronteras reales, fronteras imaginadas, Alicante, Letra de palo, 2015, pp. 363-377.

Ramón Fernández, Francisca. "Propiedad intelectual, obra coreográfica y videodanza”, en Ponencias II Encuentro Internacional de Film de Danza 2015, 25 de septiembre de 2015, Alicante, L'Eixam, 2015, pp. 29-43.

Ramón Fernández, Francisca. "El concepto de la originalidad en la videodanza: una cuestión de pasos e imagen", en Proceedings of the International Screendance Meeting, Valencia, Universitat Politècnica de València, 2016, pp. 131-140, disponible en: http://www.lalibreria.upv.es/portalEd/UpvGestore/ products/p_6352-1-1 [consultado el 8 de septiembre de 2017].

Rosen, Charles. "Influencia: inspiración y plagio", Quodlibet: Revista de Especialización Musical, n. ${ }^{\circ}$ 13, 1999, pp. 13-30.

Ruipérez García, Germán y García Cabrero, José Carlos. "Plagio e integridad académica en Alemania", Comunicar: Revista Científica Iberoamericana de Comunicación y Educación, n. ${ }^{\circ} 48,2016$, pp. 9-17, disponible en: https:// www.revistacomunicar.com/index.php?contenido=detalles\&numero=48\&art iculo=48-2016-01 [consultado el 5 de septiembre de 2017].

SÁnchez Aristi, Rafael. "Plagio de fondos musicales para 'spots': ¿̨responde el editor?", Pe.i.: Revista de Propiedad Intelectual, n. ${ }^{\circ}$ 17, 2004, pp. 31-76.

SCHNeider, Michel. Voleurs de mots: essai sur le plagiat, la psychanalyse et la pen, Paris, Gallimard, 1985. 
Soler Benito, Cristina. Propiedad intelectual en las artes escénicas, tesis doctoral dirigida por Pau Monterde, Francesc Foguet i Boreu, Universitat Autònoma de Barcelona, Barcelona, 2016, disponible en: https://ddd.uab.cat/pub/tesis/2016/ hdl_10803_381261/csb1de1.pdf [consultado el 19 de abril de 2018].

Spinak, ERnesto. "Ética editorial y el problema del plagio", en SciELO en Perspectiva, 2013, disponible en: http://blog.scielo.org/es/2013/10/02/etica-editorialy-el-problema-del-plagio/ [consultado el 10 de septiembre de 2017].

Timal López, Sandra y Sánchez Espinosa, Francisco. "El plagio en el contexto del derecho de autor", Tla-melaua: Revista de Ciencias Sociales, vol. 11, n. ${ }^{\circ} 42$, 2017, pp. 48-66, disponible en: http://www.apps.buap.mx/ojs3/index.php/ tlamelaua/article/view/281/229 [consultado el 19 de abril de 2018].

Valicenti, Ezequiel Andrés. "Los usos creativos de obra protegida por el derecho de autor frente al derecho al acceso al arte y a la cultura. Razones para pensar una nueva excepción", Cartapacio de Derecho: Revista Virtual de la Facultad de Derecho, n. ${ }^{\circ}$ 0, 2017, pp. 1-29, disponible en: http://www.cartapacio.edu.ar/ ojs/index.php/ctp/article/view/1522/2031 [consultado el 19 de abril de 2018]. 